\title{
Heat probe thermocoagulation and pure alcohol injection in massive peptic ulcer haemorrhage: a prospective, randomised controlled trial
}

\author{
H J Lin, F Y Lee, W M Kang, Y T Tsai, S D Lee, C H Lee
}

\begin{abstract}
We conducted a prospective randomised controlled trial of 137 patients with massive peptic ulcer haemorrhage over a period of 12 months to compare the haemostatic effects of endoscopic heat probe thermocoagulation and pure alcohol injection. Seventy eight patients $(56.9 \%)$ were in shock at the time of randomisation to the trial. The age, sex, number of patients in shock, haemoglobin value at the time of entry to the trial, number of patients with severe medical illness, location of bleeders, and stigmata of recent haemorrhage were comparable among the heat probe, pure alcohol, and control groups. The initial haemostatic effect of the heat probe was better than that of the pure alcohol injection (44 of 45 $v 31$ of $46, p=0.0004)$. The ultimate haemostasis achieved by the heat probe group ( 41 of 45) was better than that of the pure alcohol group ( 31 of $46, p=0.012$ ) and of controls ( 24 of $46, p=0.0001)$. The duration of hospital stay was shorter for patients in the heat probe group than for the control group (6.2 days $v 13.8$ days, $p<0.05)$. The incidence of emergency surgery was less for the heat probe than the control group (three of $45 v 12$ of $46, p=0.027$ ). The mortality rate was less in the heat probe than in the control group (one of $45 v$ seven of 46, $p=0.031$ ). We suggest that heat probe thermocoagulation should be the first treatment of choice for arrest of massive peptic ulcer haemorrhage.
\end{abstract}

Upper gastrointestinal bleeding is a common but serious clinical problem ${ }^{1-4}$ and its mortality rate has remained constant at $10 \%$ for the past 40 years. ${ }^{1-}$ About $80-90 \%$ of episodes of upper gastrointestinal bleeding stop spontaneously. ${ }^{+5}$ For these patients the hospital course is relatively smooth, with a mortality rate of $4 \%$ or less. ${ }^{36}$ In patients with severe persistent bleeding, however, the mortality rate is as high as $30-40 \%$ and emergency surgical intervention is usually required. ${ }^{37}$

In the past 10 years different methods of endoscopic haemostasis including laser photocoagulation, electrocoagulation, heat probe thermocoagulation, and injection have been tried, with varying degrees of success. ${ }^{8-38}$ Laser photocoagulation is associated with drawbacks of poor tangential application, risk of perforation, optical hazard, high expense, and imperfect haemostatic effect. ${ }^{10}$ Heat probe thermocoagulation and multipolar electrocoagulation have been reported to have excellent results in the arrest of haemorrhage. ${ }^{10-21}$ Endoscopic injection for peptic ulcer haemorrhage is easy to perform and no doubt cost effective. ${ }^{82-36}$ Unfortunately, however, only one of the reported series is a controlled study. ${ }^{27}$ Fair or poor results from endoscopic injection have also been reported..$^{2431-33}$ Because of this a controlled trial of endoscopic injection compared with the contact probe has been needed. ${ }^{26}{ }^{33-35}$ In this report we evaluate the haemostatic effects of heat probe thermocoagulation and pure alcohol injection in a prospective randomised controlled trial.

\section{Materials and methods}

Patients were accepted for this study if a bleeder (spurter or oozer) or a non-bleeding visible vessel in a peptic ulcer was seen during emergency endoscopic examination. The study was approved by the Clinical Research Committee of the Veterans General Hospital, Taipei, Republic of China. Informed consent was obtained from all patients before the trial. For each patient enrolled in the study, a sealed envelope was opened before therapeutic endoscopy to decide the form of treatment, which had been arranged by a statistician who was not involved in the clinical trial.

The first group of patients received heat probe thermocoagulation, the second group pure alcohol injection, and the third group (control subjects) received conservative treatment. Patients in the first and second groups in whom bleeding recurred received the same treatment again. If haemostasis could not ultimately be obtained in re-bleeders, they were removed from the study and received other forms of treatment.

In the control group emergency surgical intervention was performed if shock had not been corrected by $1500 \mathrm{ml}$ blood transfusion within two hours or if the total volume of transfused blood exceeded $2500 \mathrm{ml}$ within 24 hours. Patients with severe medical illness for whom surgical interventions were rejected by the surgeons were, however, excluded from the study, and they received therapeutic endoscopy for ethical reasons.

The patients' vital signs were checked every hour for 12 hours, every two hours for 12 hours, every four hours for 24 hours until they became stable, and then four times daily. A nasogastric tube was inserted and maintained in situ until 24 hours after treatment. The haemoglobin and haematocrit values were checked every day, and a blood transfusion was given if the haemoglobin concentration dropped to less than $9 \mathrm{~g} / \mathrm{dl}$ or if vital signs deteriorated. Endoscopy followed 72 hours later, and if no blood clot or haemorrhage was observed in the ulcer base, the patient 
TABLE I Characteristics of the study patients at the start of the trial

\begin{tabular}{|c|c|c|c|}
\hline & $\begin{array}{l}\text { Control group } \\
(n=46)\end{array}$ & $\begin{array}{l}\text { Heat probe } \\
\text { group } \\
(n=45)\end{array}$ & $\begin{array}{l}\text { Pure alcohol } \\
\text { group } \\
(n=46)\end{array}$ \\
\hline \multirow{6}{*}{$\begin{array}{l}\text { Age (yrs, mean (SEM)) } \\
\text { Sex }(M / F) \\
\text { No }(\%) \text { in shock } \\
\text { Haemoglobin (g/dl, mean (SEM)) } \\
\text { Applied energy (J, mean (SEM)) } \\
\text { Injected volume of pure alcohol (ml, mean (SEM)) } \\
\text { No }(\%) \text { with severe medical disease }\end{array}$} & $57(2 \cdot 3)$ & $58 \cdot 5(2 \cdot 5)$ & $57 \cdot 9(2 \cdot 2)$ \\
\hline & & & $37 / 9$ \\
\hline & $27(58 \cdot 7)$ & $27(60)$ & $24(52 \cdot 2)$ \\
\hline & $8(1 \cdot 1)$ & $\begin{array}{c}8 \cdot 2(1 \cdot 2) \\
997(136)\end{array}$ & $8(0 \cdot 7)$ \\
\hline & & & $1.76(0.17)$ \\
\hline & $7(15 \cdot 2)$ & $8(17 \cdot 8)$ & $7(15 \cdot 2)$ \\
\hline \multirow{4}{*}{$\begin{array}{l}\text { Stigmata of recent haemorrhage: } \\
\text { No (\%) with spurting haemorrhage } \\
\text { No (\%) with oozing haemorrhage } \\
\text { No (\%) with non-bleeding visible vessel }\end{array}$} & & & \\
\hline & $12(26 \cdot 1)$ & $15(33 \cdot 3)$ & $13(28 \cdot 3)$ \\
\hline & $12(26 \cdot 1)$ & $14(31 \cdot 1)$ & $15(32 \cdot 6)$ \\
\hline & $22(47 \cdot 8)$ & $16(35 \cdot 6)$ & $18(39 \cdot 1)$ \\
\hline
\end{tabular}

was discharged and followed up with endoscopy after seven days, one month, and every month until scarring of the lesion ensued.

If unstable vital signs or continued tarry or bloody stools were observed during the stay in hospital, emergency endoscopy was performed to determine whether any additional treatment was needed. Re-bleeding was defined as blood in the stomach 24 hours after treatment, bleeding in the ulcer base, presence of unstable vital signs and continued tarry bloody stools, or haematemesis after treatment.

A visible vessel at endoscopy was defined as a red or black spot raised from the ulcer base which was resistant to washing and was often associated with the freshest clot in the ulcer base. Shock was defined as systolic pressure less than $100 \mathrm{mmHg}$ and a pulse rate greater than 100 $\mathrm{bpm}$. The initial success of treatment was defined as haemostasis persisting for five minutes after treatment. Ultimate success of treatment was defined as lack of re-bleeding for seven days after treatment.

In the heat probe group, we used an Olympus GIF-1T10 or GIF-2T10 panendoscope and an Olympus heat probe unit to treat the patients. During treatment, the distal tip of the probe was applied directly to the bleeding site with moderate force. Initially $15-20 \mathrm{~J} /$ pulse were delivered, and this was increased as needed to 30 $\mathrm{J} /$ pulse until the red base turned black. Then the top of the probe was applied circumferentially around the bleeding site with 15-20 J/pulse for four to eight pulses. The bleeding site was observed for five minutes. At the end of this time, the bleeding site was challenged with maximal water irrigation for 10 seconds. If any further haemorrhage occurred, the above pro-

TABLE II Comparison of results in heat probe (HP) thermocoagulation, pure alcohol (PA), and control groups in patients with massive peptic ulcer haemorrhage

\begin{tabular}{|c|c|c|c|}
\hline & $\begin{array}{l}\text { Control group } \\
(n=46)\end{array}$ & $\begin{array}{l}\text { Heat probe } \\
\text { group } \\
(n=45)\end{array}$ & $\begin{array}{l}\text { Pure alcohol } \\
\text { group } \\
(n=46)\end{array}$ \\
\hline $\begin{array}{l}\text { No }(\%) \text { with successful initial haemostasis } \\
\text { No }(\%) \text { with rebleeding } \\
\text { No }(\%) \text { with successful repeat haemostasis } \\
\text { No (\%) with ultimate haemostasis } \\
\text { Blood transfusions (U, mean (SEM)) } \\
\text { No (\%) receiving emergency surgery (\%) } \\
\text { Days in hospital (mean (SEM)) } \\
\text { Mortality rate }\end{array}$ & $\begin{array}{c}24(52 \cdot 2) \\
7 \cdot 1(1 \cdot 1) \\
12(26 \cdot 1) \\
13 \cdot 8(2 \cdot 4) \\
7(15 \cdot 2)\end{array}$ & $\begin{array}{l}44(97 \cdot 8) \\
8(18 \cdot 2) \\
5(62 \cdot 5) \\
41(91 \cdot 1) \\
7 \cdot 5(1 \cdot 2) \\
3(6 \cdot 7) \\
6 \cdot 2(0 \cdot 7) \\
1(2 \cdot 2)\end{array}$ & $\begin{array}{l}31(67 \cdot 4)^{\star \star} \\
2(6 \cdot 5)^{\star} \\
2(100)^{\star} \\
31(67 \cdot 4) \# \\
5 \cdot 7(0 \cdot 7)^{\star} \\
2(4 \cdot 3) \dagger \\
9 \cdot 0(1 \cdot 1) \# \# \\
0(0)+t\end{array}$ \\
\hline
\end{tabular}

${ }^{\star} \mathrm{p}>0.05,{ }^{\star \star} \mathrm{p}=0.0004$.

tp $=0.0024(p=0.027$ between controls and HP, $p=0.009$ between controls and PA)

$\# p=0.0002(p=0.0001$ between controls and HP, $p=0.012$ between PA and HP)

$\# \# \mathrm{p}<0.05$ between HP and controls. Others: $\mathrm{p}>0.05$

$+\mathrm{p}=0.002(\mathrm{p}=0.031$ between controls and HP, $p=0.018$ between controls and $\mathrm{PA})$ cedure was repeated until no more bleeding was seen.

In the pure alcohol injection group, we used an Olympus GIF-P10 or Olympus GIF-2T10 panendoscope and an Olympus injector NM8-L to treat the patients. We injected $99.8 \%$ alcohol (E Merck, West Germany) $0.3-0.5 \mathrm{ml}$ at every quadrant and $1-2 \mathrm{~mm}$ away from the bleeder, with a total volume of $1-2 \mathrm{ml}$. Then we observed the ulcer for five minutes. If the bleeding had stopped, we withdrew the endoscope.

We used the ANOVA test to compare the basic data of age, volume of blood transfusion, and haemoglobin among the three groups, Kruskal-Wallis ANOVA test to compare the duration of hospital stay among the three groups, the $\chi^{2}$ test, with or without Yates' correction, and Fisher's exact test, when appropriate, to compare the haemostatic effects among the three groups. A probability value of less than 0.05 was considered significant.

\section{Results}

Between August 1987 and July 1988, a total of 1240 patients visited the emergency department with a chief complaint of upper gastrointestinal bleeding. Nine hundred and thirty of these patients underwent emergency endoscopy within 12 hours of arrival. We failed to identify bleeders in eight patients. We found peptic ulcers with bleeding (oozing or spurting) or nonbleeding visible vessels in 141 other patients. We explained the details of this clinical trial to each patient and his or her family before emergency endoscopy was performed. Four of the 141 patients refused to enter the trial.

The age, sex, number of patients in shock, haemoglobin values, number of patients with severe medical illness, and stigmata of recent haemorrhage in the three groups were not statistically different (Table I).

We enrolled 46 patients in the control group. Twenty four of them had an uneventful course over the following weeks, except for two who had re-bleeding episodes three to four days later which subsided spontaneously (Table II). Conservative management of the other 22 patients failed, as shown by continuing bleeding. Twelve of these 22 patients underwent emergency surgery; one patient underwent transcoeliac artery embolisation; five patients with severe medical illness underwent therapeutic endoscopy (four for heat probe and one for pure alcohol haemostasis) for ethical reasons; two patients died of unrelated medical illness; and two patients died of massive haemorrhage while awaiting surgery.

In the heat probe group, 44 patients $(97 \cdot 8 \%)$ achieved initial haemostasis. The only patient in whom this failed was withdrawn from the study. Of the 44 patients who had achieved initial haemostasis, eight $(18 \cdot 2 \%)$ re-bled within seven days. These eight underwent a second heat probe thermocoagulation and five $(62.5 \%)$ attained ultimate haemostasis. In the end ultimate haemostasis was achieved in 41 patients $(91 \cdot 1 \%)$ (Table II).

In the pure alcohol group, 31 patients $(67 \cdot 4 \%)$ achieved initial haemostasis. Two of them re- 
TABLE III The ability to stop bleeding in relation to the location of the peptic ulcers among the three groups

\begin{tabular}{|c|c|c|c|c|}
\hline $\begin{array}{l}\text { Location of } \\
\text { bleeders }\end{array}$ & $\begin{array}{l}\text { Control } \\
\text { group } \\
(n=46)\end{array}$ & $\begin{array}{l}\text { Heat probe } \\
\text { group } \\
(n=45)\end{array}$ & $\begin{array}{l}\text { Pure alcoh } \\
\text { group } \\
(n=46)\end{array}$ & \\
\hline $\operatorname{ardi}$ & - & $1 / 1$ & $2 / 2-2 \cdot(-1)$ & \\
\hline Body of stomach & $4 / 9$ & $12 / 14^{\star}$ & $8 / 16^{\star}$ & ${ }^{\star} \mathrm{p}=0.0$ \\
\hline Antrum & $3 / 8^{\star}$ & $8 / 8^{\star}$ & $4 / 5$ & ${ }^{\star} \mathrm{p}=0.013$ \\
\hline Duodenal bulb & $17 / 28^{\star}$ & $18 / 19 \star$ & $17 / 23$ & ${ }^{*} \mathrm{p}=0.0083$ \\
\hline Marginal ulcer & $0 / 1$ & $2 / 3$ & - & NS \\
\hline
\end{tabular}

bled within seven days of the injection. These two patients achieved ultimate haemostasis after the second injection treatment. Fifteen patients who had failed to achieve initial haemostasis were withdrawn from the study and underwent heat probe thermocoagulation. Thirteen of these patients achieved ultimate haemostasis; the two others underwent surgery (Table II).

The initial haemostasis was better in the heat probe group than in the pure alcohol group $(\mathrm{p}=$ $0.0004)$. Re-bleeding rates in the heat probe and pure alcohol groups were $18 \cdot 2 \%$ (eight of 44 ) and $6.5 \%$ (two of 31 ) respectively $(\mathrm{p}=0.087$ ). With the second treatment for re-bleeders we achieved an ultimate haemostatic rate of $62.5 \%$ (five of eight) in the heat probe group and $100 \%$ (two of two) in the pure alcohol group ( $p=0.41)$. The ultimate success rates in the control, heat probe, and the pure alcohol groups were $52 \cdot 2 \%$ (24 of 46 ), $91 \cdot 1 \%$ (41 of 45 ), and $67 \cdot 4 \%$ (31 of 46 ), respectively. Heat probe thermocoagulation was better than conservative treatment or pure alcohol injection in achieving ultimate haemostasis $(p=0.0001, p=0.012$, respectively). There was no statistically significant difference in the haemostatic effects between the pure alcohol and the control groups $(p=0 \cdot 2)$ (Table II).

The duration of hospital stay was significantly less in the heat probe group compared with the control group ( 6.2 days $v 13.8$ days, $\mathrm{p}<0.05)$. Emergency surgery for persistent or recurrent bleeding was required in $12(26 \cdot 1 \%$ of the control subjects and in three patients $(6 \cdot 7 \%)$ in the heat probe group. The heat probe group had a statistically lower emergency surgery rate than the control group $(\mathrm{p}=0 \cdot 027)$.

Seven patients in the control group died - as the result of surgical complications in two, failure of embolisation to halt bleeding in one, severe exsanguination in two, and severe medical illness in two. One patient from the heat probe group and none from the pure alcohol group died of massive haemorrhage. The mortality rate was significantly lower in the heat probe group than in controls (one of $45 v$ seven of $46, p=0.031$ ). No complications related to therapeutic endoscopy were observed in the heat probe or pure alcohol groups.

After analysing the ability to halt bleeding in relation to the location of the bleeding among

TABLE IV The ultimate haemostatic effects among the three groups in relation to stigmata of recent haemorrhage

\begin{tabular}{|c|c|c|c|c|}
\hline \multirow{2}{*}{$\begin{array}{l}\text { Stigmata of recent haemorrhage } \\
\text { Spurting haemorrhage }\end{array}$} & \multirow{2}{*}{$\frac{\begin{array}{l}\text { Control group } \\
(n=46)\end{array}}{3 / 12 \dagger}$} & \multirow{2}{*}{$\frac{\begin{array}{l}\text { Heat probe group } \\
(n=45)\end{array}}{13 / 15 \dagger \#}$} & \multicolumn{2}{|c|}{$\begin{array}{l}\text { Pure alcohol group } \\
(n=46)\end{array}$} \\
\hline & & & 4/13\# & $t p=0.0018$ \\
\hline $\begin{array}{l}\text { Oozing haemorrhage } \\
\text { Non-bleeding visible vessel }\end{array}$ & $\begin{array}{l}6 / 12^{\star} \\
15 / 22\end{array}$ & $\begin{array}{l}14 / 14^{\star} \\
14 / 16\end{array}$ & $\begin{array}{l}12 / 15 \\
15 / 18\end{array}$ & $\begin{array}{l}{ }^{\star} \mathrm{p}=0 \cdot 0040 \\
\mathrm{NS}\end{array}$ \\
\hline
\end{tabular}

three groups, we conclude that the heat probe thermocoagulation was effective in any site of the stomach and duodenum whereas pure alcohol injection was less effective (Table III). An investigation into the relation between haemostatic effects and the stigmata of recent haemorrhage among the three groups showed that the heat probe group achieved a better haemostatic result than control subjects in ulcers with spurting haemorrhage $(p=0.0018,95 \%$ confidence interval on difference $=0.32-0.92$ ) and oozing haemorrhage $(p=0.004,95 \%$ confidence interval on difference $=0 \cdot 72-1 \cdot 28$, and a better result than the pure alcohol group in ulcers with spurting haemorrhage $(\mathrm{p}=0.0037,95 \%$ confidence interval on difference $=0 \cdot 26-0 \cdot 86$ ). In patients with non-bleeding visible vessels there was no statistically significant difference in haemostasis achieved among the three groups (Table IV).

\section{Discussion}

Since 1978 heat probe thermocoagulation has been reported as an excellent means of achieving haemostasis. ${ }^{10-1934}$ Pure alcohol injection has also been reported to be highly effective in achieving haemostasis. ${ }^{822-28}$ Some questions have been raised, however, about injection therapy. ${ }^{12}{ }^{33}$ The detailed sites of bleeders were not mentioned, ${ }^{22-27}$ and the number of massive haemorrhages reported was small. ${ }^{8222426}$ Therefore, a randomised controlled trial has been needed to evaluate the haemostatic effect of injection therapy. ${ }^{26}$ 33-35

In our series massive haemorrhage was apparent in most patients. Seventy eight (56.9\%) patients were in shock at the time of entry to the trial. The average volume of blood transfusion in the three groups was $7 \cdot 1 \mathrm{U}$ (control subjects), $5.7 \mathrm{U}$ (pure alcohol group), and 7.5 $\mathrm{U}$ (heat probe group).

The ultimate haemostatic rate of the heat probe group in our series was high, up to $91 \cdot 1 \%$ (41 of 45). This result is similar to those reported by other authors ${ }^{1017}$ and in our previous uncontrolled series. ${ }^{11-14}$ The ultimate haemostatic rate of pure alcohol injection in our series was $67 \cdot 4 \%$ (31 of 46). This result is lower than those reported by some authors ${ }^{81022-28}$ but is comparable with our previous report and those of other authors. ${ }^{123132}$

In reports discussing the haemostatic effect of endoscopic injection, Leung and Chung ${ }^{22}$ found that it was difficult to inject bleeders located on the floor or posterior wall of the duodenal bulb; Sugawa et $\mathrm{l}^{8}$ excluded two patients in their series because of a poor tangential approach; Panes et $a l^{27}$ also excluded seven patients for the same reasons. The 15 patients who failed to achieve haemostasis in our series included nine with spurting haemorrhage and six with bleeders that were difficult to approach en face (two bleeders located over the posterior wall of the duodenal bulb, two over the posterior wall of the midbody of the stomach, and two over the lesser curvature of the high body of the stomach). Failure to manage the difficult to approach bleeders and spurting bleeders are two main causes for the low haemostatic rate achieved in the pure alcohol group. In the heat probe group we had no such 
problem.. Since the side of the distal tip of the probe can be applied to thermocoagulate the bleeder, tangential probe application is more feasible than pure alcohol injection. ${ }^{1012} 20$ In our series, the haemostatic rate for the heat probe group was better than that for the pure alcohol group for bleeders located over the posterior wall of the gastric body or duodenum (15 of $15 v$ four of $8, p=0 \cdot 015$ )

With regard to the volume of pure alcohol needed to stop the haemorrhage, Sugawa et al suggested that a volume of less than $1 \mathrm{ml}$ be used to avoid perforation. We believe that this volume may be too little to arrest a spurting bleeder ${ }^{12}$ and therefore we injected 1-2 ml pure alcohol around each bleeder and up to $3.5 \mathrm{ml}$ in two cases without perforation. A larger volume of other solutions (eg, hypertonic saline, epinephrine, or polidocanol) may be more effective in arresting spurting haemorrhage. ${ }^{36}$

In ulcers with spurting haemorrhage, the special irrigation system of the heat probe enabled us to irrigate and compress the bleeder simultaneously, thus ensuring compression of the bleeder before thermocoagulation..$^{1020}$ The heat sink effect was thus diminished ${ }^{9}$ and damage to the normal mucosa was also avoided. ${ }^{9} \mathrm{~A}$ total of 40 patients with spurting haemorrhage entered our study. This number of patients is larger than those reported by other authors. ${ }^{10}$ is $1722-2529$ Patients with peptic ulcer and spurting haemorrhage have an $85 \%$ incidence of further haemorrhage and a mortality rate of $50 \% .{ }^{39+0}$ They usually require surgery or therapeutic endoscopy..$^{34} 39$. In our control subjects spurting haemorrhage subsided spontaneously in only three of 12 . The other nine patients required either surgical intervention or therapeutic endoscopy. In our opinion patients with peptic ulcer and spurting haemorrhage comprise a more severely ill group, for whom immediate aggressive management is needed.

Peptic ulcer patients with oozing haemorrhage have a mortality rate of $13 \cdot 3 \%$ - four to five times that of patients whose ulcers have a clean base. ${ }^{+0}$ In our control subjects, half (six of 12) with oozing haemorrhage could be managed conservatively. In ulcers with oozing haemorrhage, the haemostatic effect was significantly better in the heat probe group than in the control group. Although the haemostatic effect was better in the pure alcohol group than in the control group, the difference was not statistically significant, perhaps because of the small number of patients. We suggest that patients with oozing peptic ulcers be treated with heat probe thermocoagulation as the first treatment of choice.

The re-bleeding rate for peptic ulcers with a visible vessel was estimated to be $33-100 \% .^{12}+6$ Whether a peptic ulcer with a non-bleeding visible vessel needs aggressive treatment remains a matter of controversy. ${ }^{39+3+16+7}$ In the control group, $11(50 \%)$ patients re-bled and seven $(31.8 \%)$ patients required surgery or therapeutic endoscopy. The ultimate haemostatic rates in peptic ulcer patients with non-bleeding visible vessels were better (though not statistically significant) in the heat probe and pure alcohol groups than in the control group. The number of patients may be too small to result in a statistic- ally significant difference and should be increased to 107 for each group to be statistically significant (alpha error: $0 \cdot 05$, beta error: $0 \cdot 10$ ).

We conclude that therapeutic endoscopy is necessary in peptic ulcers with oozing or spurting haemorrhage. Heat probe thermocoagulation can achieve a much higher haemostatic rate, shorten the length of hospital stay and reduce the incidence of surgery and mortality. It should therefore be the first treatment choice in the management of peptic ulcers with spurting and oozing haemorrhage. We also look forward to a larger series of controlled trials to determine whether non-bleeding visible vessels require aggressive management.

1 Allan R, Dykes P. A study of the factors influencing mortality rates from gastrointestinal hemorrhage. $Q \mathcal{F}$ Med 1976; 45 533-50.

2 Silverstein FE, Gilbert DA, Tedesco FJ, Buenger NK, Persing J. The national ASGE survey on upper gastrointestinal bleeding. Gastrointest Endosc 1981; 27: 73-9.

3 Fleischer D. Etiology and prevalence of severe persistent upper gastrointestinal bleeding. Gastroenterology 1983; 84: upper gastr.

4 Silverstein FE, Feld AD, Gilbert DA. Upper gastrointestinal tract bleeding. Arch Intern Med 1981; 141: 322-7.

5 Northfield TC. Factors predisposing to recurrent haemorrhage after acute gastrointestinal bleeding. Br Med f 1971; i 26-8

6 Schiller KFR, Truelove SC, Gwyn Williams D. Haematemesis and melena, with special reference to factors influencing the outcome. BrMed F 1970; ii: 7-14.

$7 \mathrm{MaCleod}$ IA, Mills PR. Factors identifying the probability of further haemorrhage after acute upper gastrointestinal haemorrhage. Br $\mathcal{A}$ Surg 1982; 69: 256-8.

8 Sugawa C, Fujita Y, Ikeda T, Walt AJ. Endoscopic hemostasis of bleeding of the upper gastrointestinal tract by local injection of ninety-eight per cent dehydrated ethanol. Surg Gynecol Obstet 1986; 162: 159-63.

9 Johnston JH, Jensen DM, Auth D. Experimental comparison of endoscopic yttrium-aluminum-garnet laser, electrosurgery, and heater probe for canine gut arterial coagulation. Gastroenterology 1987; 92: 1101-8.

10 Johnston JH, Sones JQ, Long BW, Leonard Posey E Comparison of heater probe and YAG laser in endoscopic treatment of major bleeding from peptic ulcers. Gastrointes Endosc 1985; 31: 175-80.

11 Lin HJ, Tsai YT, Lee SD, et al. Treatment of severe peptic ulcer haemorrhage with the heat probe. $\mathcal{F}$ Gastroenterol Hepatol 1988; 3: 77-81.

$12 \mathrm{Lin} \mathrm{HJ}$, Tsai YT, Lee SD, et al. A prospectively randomized trial of heat probe thermocoagulation versus pure alcohol injection in nonvariceal peptic ulcer hemorrhage. Am $\mathcal{J}$ Gastroenterol 1988; 83: 283-6.

13 Lin HJ, Tsai YT, Lee SD, et al, Heater probe thermocoagula tion for patients in shock following massive peptic ulcer tion for patients in shock following massive pepti

14 Lin HJ, Tsai YT, Lee SD, Lai KH, Lee CH. Heat probe therapy for severe peptic ulcer hemorrhage with a visible vessel. Endoscopy 1988; 20: 131-3.

15 Shorvon PJ, Leung JWC, Cotton PB. Preliminary clinica experience with the heat probe at endoscopy in acute upper gastrointestinal bleeding. Gastrointest Endosc 1985; 31: $364-6$.

16 Papp JP. Heat probe versus BICAP probe in the treatment of upper gastrointestinal bleeding. Am F Gastroenterol 1987; 82: 619-21.

17 Jensen DM, Machicado GA, Silpa ML. Argon laser vs. heater probe or BICAP for control of severe ulcer bleeding probe or BICAP for control of severe ul. Gastrointest Endosc 1984; 30: A 134

18 Storey DW. Endoscopic control of peptic ulcer haemorrhage using the heater probe [Abstract]. Gut 1983; 24: A967-8.

19 Jensen DM, Machicado GA, Tapia JI, Beilin DB. Clinical hemostasis with heater probe or bipolar electrocoagulation for severe gastrointestinal bleeding [Abstract]. Gastrointest Endosc 1983; 29: A 162

20 Protell RL, Rubin CE, Auth DC, et al. The heater probe: a new endoscopic method for stopping massive gastrointestinal bleeding. Gastroenterology $1978 ; 74: 257-62$.

21 Laine L. Multipolar electrocoagulation in the treatment of active upper gastrointestinal hemorrage. $N$ Engl $\mathcal{f} \mathrm{Med}$ 1987; 316: 1613-7.

22 Leung JWC, Chung SCS. Endoscopic injection of adrenalin in bleeding peptic ulcers. Gastrointest Endosc 1987; 33: 73-5.

23 Wordehoff D, Gros H. Endoscopic haemostasis by injection therapy in high-risk patients. Endoscopy 1982;14: 196-9.

24 Fuchs KH, Wirtz HJ, Schaube H, Elfeldt R. Initial experience with thrombin as injection agent for bleeding gastroduodenal lesions. Endoscopy 1986;18: 146-8.

25 Soehendra N, Grimm H, Stenzel M. Injection of nonvariceal bleeding lesions of the upper gastrointestinal tract. Endoscopy 1985; 17: 129-32.

26 Di Felices G. Endoscopic injection treatment in patients with shock and gastrointestinal bleeding or stigmata of recent hemorrhage. Endoscopy 1987; 19: 185-9. 
27 Panes J, Viver J, Forne M, Garcia-Olivares E, Marco C, Gara $\mathrm{J}$. Controlled trial of endoscopic sclerosis in bleeding peptic ulcers. Lancet 1987; ii: 1292-4.

28 Hirao M, Kobayashi T, Masuda K, et al. Endoscopic loca injection of hypertonic saline-epinephrine solution to arrest hemorrhage from the upper gastrointestinal tract. Gastrointest Endosc 1985; 31: 313-7.

29 Krejs GJ, Little KH, Westergaard H, Hamilton JK, Spady DK, Polter DE. Laser photocoagulation for the treatment of acute peptic ulcer bleeding. $N$ Engl $\mathcal{F}$ Med 1987; 316: 161821 .

30 Asaki S, Nishimura T, Satoh A, et al. Endoscopic hemostasis of gastrointestinal hemorrhage by local application of absolute alcohol: a clinical study. Tohoku $\mathcal{F} \operatorname{Exp}$ Med 1983; 141: 373 .

31 Rutgeerts P, Broeckaert L, Coremans G, Janssens J, Van Isveldt J, Vantrappen G. Randomized comparison of three hemostasis modalities for severely bleeding peptic ulcer [Abstract]. Gastrointest Endosc 1987; 33: A 182

32 Hajiro $K$. Japanese experience with local injection and hemoclips. Symposium on endoscopy in upper GI bleeding, XIIth Int Gastroenterology Cong, Vth Eur Gastrointestina Endoscopy Cong. Lisbon, September, 1984.

33 Schuman BM. Endoscopic injection therapy for nonvariceal upper gastrointestinal hemorrhage - is it too good to be true? Gastrointest Endosc 1987; 33: 121-2.

34 Johnston JH. Endoscopic hemostasis for bleeding peptic ulcer. Gastrointest Endosc 1987; 33: 260-2

35 Valenzuela GA, Lind CD, Pambianco DJ, Stone DD. Injection therapy for nonvariceal hemorrhage. Gastrointest Endosc 1987,

36 Masuyama H, Kano A. Comparative study on haemostatic effect of endoscopic local injection with hypertonic salin epinephrine solution (HS-E) and with pure ethanol (PE) for acute upper GI bleeding [Abstract]. Gastroenterol Endos
1983; 25: 1616-9.

37 Brunetaud JM, Jensen DM. Current status of argon laser hemostasis of bleeding ulcers. Endoscopy 1986; 18: 40-5

38 Halprin A, Anselm K. Nd:YAG laser in treatment of seriously ill patients with gastrointestinal bleeding. Gastrointest Endosc 1986; 32: 199-201.

39 Johnston JH. The sentinel clot/visible vessel revisited. Gastrointest Endosc 1986; 32: 238-9.

40 Pimpl W, Boeckl O, Waclawiczek HW, Heinerman. Estimation of the mortality rate of patients with severe gastroduodenal hemorrhage with the aid of a new scoring system. Endoscopy 1987; 19: 101-6.

41 Domschke W, Lederer P, Lux G. The value of emergency endoscopy in upper gastrointestinal bleeding: review and endoscopy in upper gastrointestinal bleeding: re
analysis of 2014 cases. Endoscopy 1983; 15: 126-31

42 Swain CP, Storey DW, Bown SG, et al. Nature of the bleeding vessel in recurrently bleeding gastric ulcers. Gastroenterolog 1986; 90: 595-608.

43 Bornman PC, Theodorou NA, Shuttleworth RD, Essel HP, Marks IN. Importance of hypovolaemic shock and endoscopic signs in predicting recurrent haemorrhage from peptic ulceration: a prospective evaluation. $\operatorname{Br} M e d \mathcal{F} 1985$; 291: $245-7$.

44 Wara P. Endoscopic prediction of major rebleeding prospective study of stigmata of hemorrhage in bleeding prospective study of stigmata of hemo

45 Storey DW, Bown SG, Swain CP, Salmon PR, Kirkham JS, Northfield TC. Endoscopic prediction of recurrent bleeding Northfield TC. Endoscopic prediction of recurre
in peptic ulcers. N Engl f Med 1981; 305: 915-6.

46 Griffiths WJ, Neumann DA, Welsh JD. The visible vessel as an indicator of uncontrolled or recurrent gastrointestina hemorrhage. N Engl F Med 1979; 300: 1411-3.

47 Fuster F, Piqué JM, Terés J, Bordas JM, Perez. RM, Rodés J. Predictive clinical factors of visible vessel in bleeding peptic ulcer. Endoscopy 1987; 19: 11-3. 